\title{
Soulbodies lived
}

Seeing-imagining has replaced significations, identification, familiarity, and comfortable knowing. Darkness of the forest produces an experimental sacred space where one-inrelation-to-another can sense solitude in silence. Ontologies of forest belong to soulbodies; bodies that see through the souls. Soulbodies in the darkness create some unexpected connections; seeing is no longer possible but sensing is. The bodies vision differently and their mood is different. Subjects and objects emerge since their boundaries are no longer recognizable. Soulbodies question daytime's certainties. Intensity in the forest creates wolf-ness, tree-ness, to-gather-ness, astray-ness, rain-ness among other things always unexpected ways.
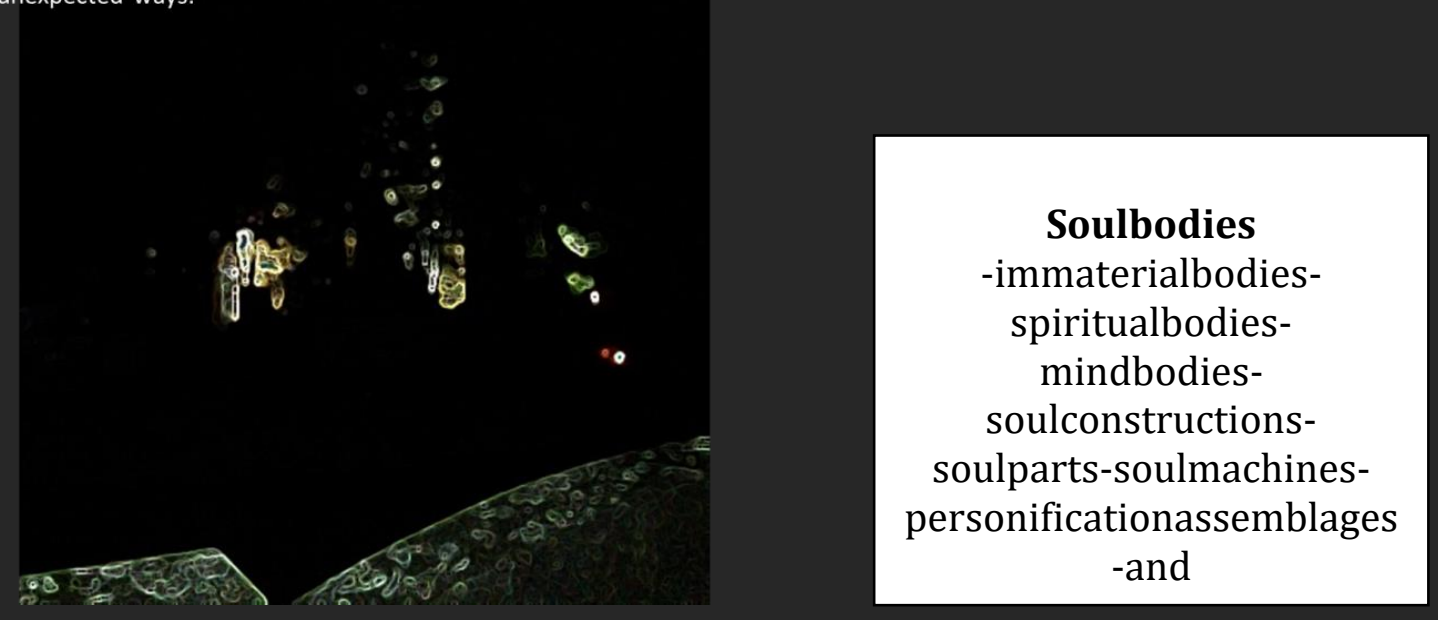

Note: This section displays a textual/visual experiment which asks readers to get lost and confused as many ways as possible. This experiment also contains spaces where readers can add their own locally and historically situated formations of soulbodies.

-nomadic objects/forest explorers- one-as-many- seeing and

being seen- soulbodies- series of ideas-

infinite series of forest matter

series of infinite forest matter

matter of infinite forest series

forest of infinite series
"Ideas are concrete universals in

which extensions and

comprehensions go together - not

only because they include variety or

multiplicity in themselves, but

because they include singularity in

all its varieties" (Deleuze, 1994, $p$.

176). 
Forest inquiries can take human forms. Forest inquiries inquire the forest and its (un)known and (un)anticipated ways to know and sense. In dark Scandinavian fall forest many assumptions about knowing and existing perceptions about methodology and scholarship are being challenged. Similarly, in a dark forest visitors and scholars as mattering nomadic objects/forest explorers experience darkness, rethink knowing, sense their bodies, and construct their belonging and relationality to not-self and Derridian Other (of the forest) potentially unexpected ways. Knowing and processes of inquiring practiced in indoor observation places, clean interview spaces, under bright video lights, and within other spaces of clear sound and vision can no longer be applied in dark forest contexts. Dark forest challenges, calls in, and anticipates the pull of various human and material forces in this continuously changing environment. Historically and culturally Finnish forests have been places and spaces of exploration, survival, diverse intentions, relaxation, and various other forms of existing and becoming. Rain, mist, trees, branches, leaves, still human bodies, animals, sounds, and lights recreate new interactive events alongside with moving and feeling scholarly bodies. In the forest soulbodies are paying attention but attention is also paid to them. Forest, its associations, smells, textures, sounds, and movement remind its visitors that everything is ever changing and as such can be always dangerous. Alternative epistemologies and methodologies need to be invented, thought and maybe borrowed.

In addition, dark forest invites and calls for (un)explored onto-epistemological practices that produce methods and methodologies differently. These methodological approaches or practices cannot be necessarily described in detail or repeated at a later time but they are sensed (see also Deleuze, 1990; Koro-Ljungberg, 2016) or maybe "lived-without-life" (Laruelle, 2013). Controllable, systematic, and predictable inquiries transform into unexpected encounters of wonder and moments of surprise. 
During the process of reimagining a 'body to become' a thin singular branch of willow converts into car's windshield wipers that clear driver's vision during the rain and foggy driving conditions. Materia, bodies, and even seemingly unrecognizable objects change. In some ways inquiry transforms from knowing others to knowing oneself(s) until another external force of otherness impacts the movement of walking and sensing singular body. Methodologies (of and in darkness as well as other kinds) question, palpate, wonder, fill in, stay open, and imagine becoming and disappearing bodies.

Ontological indeterminacy, a radical openness, an infinity of possibilities, is at the core of mattering. How strange that indeterminacy, in its infinite openness, is the condition for the possibility of all structures in their dynamically reconfiguring in/stabilities. Matter in its iterative materialization is a dynamic play of in/determinacy. Matter is never a settled matter. It is always already radically open. Closure cannot be secured when the conditions of im/possibilities and lived indeterminacies are integral, not supplementary, to what matter is (Barad, 2012, p. 214-215)

In addition, sensing and seeing in a forest creates infinite (methodological) possibilities. In a dark forest shades and shadows become more nuanced and colorful, sounds more extreme and multiplied, and smells more dense and

\section{Insert your soulbodies}

here: 
overlapping. Would this be likely to happen in a controlled research context or during premeditated interactions with study participants?

In a dark forest not only the inquirers but also the inquiry connected process sensitizes itself and adapts to the heightened sensory dimensions of forest experience. Seeing as we (scholars, post-qualitative researchers, women, friends, mothers, wonderers, theoretical nomads and so on) have come to think of it is no longer possible in the absence of light, familiar or recognizable signification. Inquiry loses its vision and possible its capability to orient and guide based on existing visual knowledge and known pictorial understandings of ourselves and our environments. Would this be likely to happen in a controlled research context or during premeditated interactions with study participants?

In some ways nomadic objects/forest explorers become impaired and less-human through the loss of predictability, rationality, and sensory based reasoning. At the same time something else productive and provocative happens. Inquiries and inquirers find their ways through branches, wet moss, rain drops, warm and cold bodies, gloves, boots, and distorted sounds of highways, cars, and overstepped grass. New questions arise. How to get around invisible obstacles without falling? How to move without walking? How to hear others without being close? How to know what to do next? How to see without seeing? How to imagine more? How to inquire? And is inquiry no longer desirable?

It is possible that seeing-imagining replaces clear views, significations, identification, familiarity, and comfortable knowing that heavily relies on eye sight and recognizable ways to sense the world and our surroundings. What might scholarship look like in the absence of clear views, without a need to signify and identify, or to declare strange only in the relation to the familiar? What could be accomplished through uncomfortable knowing in uncomfortable and strange contexts? Furthermore, what 
happens when ideas move away from binaries such as familiar and unfamiliar and every idea becomes always more than one (see Manning, 2013)? From this perspective ideas, inquiries, 'methodologies', and soulbodies are processual fields of relations and all forms and identities are complex ecological processes (Manning, 2013).

It is also possible that seeing-imagining in dark forest (or other spaces of 'limited visibility') happens in a context of relations and relationality outside and sometimes alongside human bodies and visible objects. Nomadic objects/forest explorers might sense themselves through molecules of wet air, feel extensions of cold fingers, or hear sounds of metal casings of the flashlight not as separate sensations but entangled compositions of collective entities which might be recognized as formations of soulbodies. It might feel like the Other of forest takes over, takes charge, and nomadic objects/forest explorers cannot but yield to the unexpected and follow the doing of the dark unknown. "Follow the leader, follow the leader" is called out somewhere. Focus shifts from conceptual methodological consideration to sensing the rain drops, touching cold bark, warming up cold hands, calling out others' names in an attempt to make a contact with endlessly new and unexplored surroundings. Maybe inquiry is no longer (as we have come to know it).

Maybe darkness. Maybe soulbodies. Maybe methodologies.

Shadows and holes can take over and become a temporary point of contact in the darkness. Shadows "are offspring of luminosity, kindred alter egos to sensuous things, stalking silhouettes but loyal companions of material objects" (Macauley, 2009, p. 54). Alternatively, Sorensen (2008) views shadows as holes in light. Darkness can be experienced through degrees and darkness can be a successful representation of lightness absence or absence of lightness. Negative ontology 
produces visual infinity. Subjects and objects merge in contact and transform in their oneness since their boundaries are no longer recognizable. One and many unites through doing and by acting.

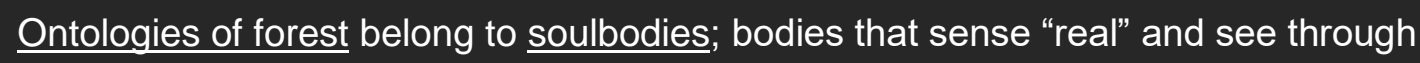
the "souls". Soulbodies of the darkness create some unexpected connections; seeing is and is not no longer possible but sensing might be. Human bodies dissolve in the darkness, become invisible and inseparable from tree branches and wet moss through walking, fade away as infinite shades of gray, disappear through the shadows, and move away from the glowing lights. Soulbodies are shifting mixtures of human and non-human interacting in various ways; synthesis of One and the Multiple; souls-bodies, forest-rain, knowing-unknowing, familiar-strange. These soulbodies sense in the dark, they experience inquiry and methodology differently, and their mood is different and beyond the ocular. Soulbodies question daytime's certainties and it is possible that they have not seen the daylight. Intensity in the forest creates shadow-ness, wolf-ness, tree-ness, to-gather-ness, astray-ness, soulbody-ness, rain-ness among other unexpected thing and dream-like sensations. This shifting and unexpected intensity also displays and multiplies soulbodies' transformations.

Nomadic objects/forest explorers might become more than one and 'one-as-many' (as 'many' differentiating within itself) who can only imagine various ways of seeing and being seen / seeing and not being seen not seeing and being seen / not seeing and not being seen. 

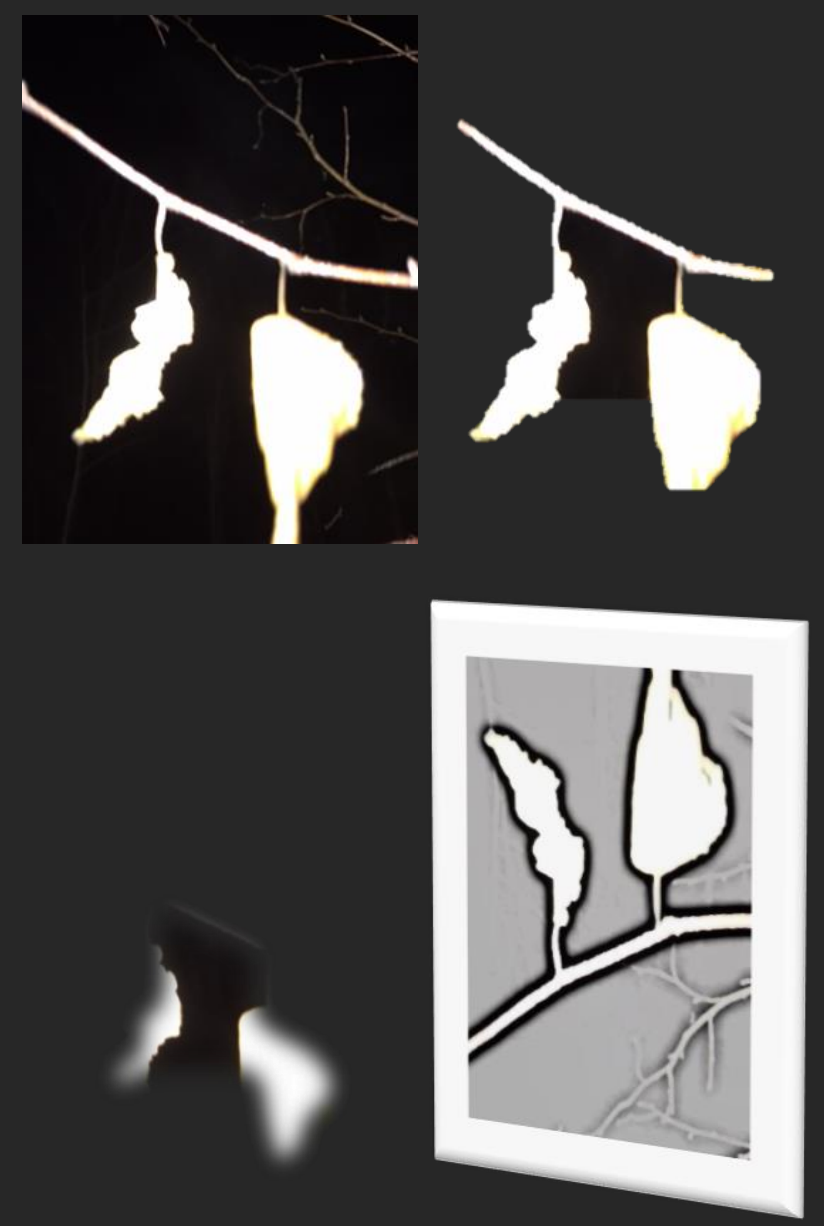

One-as-many soulbodies stimulate variation and further produce endless series of changing forest matter. Differing within itself dark forest and forest soulbodies move forward and backwards, branches shift from left to right, sounds become louder and then silence again. Forest is moving and differentiating within itself simultaneously changing thinking, sensing, and knowing of subjects and objects during the process of reimagining. The context of dark forest is a moving platform and self-differentiating matter for soulbody inquiry. Dark forest frames, sets up, composes, unities, and separates. "Difference allows the passage from similar neighbouring species to the identity of a genus which subsumes them- that is, the extraction or cutting out of generic identities from the flux of a continuous perceptible series" (Deleuze, 1994, p. 34). Deleuze (1994) refers to the orgiastic representation which "discovers within itself the limits of the organized" (p. 42), the unassignable movement between 
polarities, and the restlessness underneath the calm. Orgiastic representation of the soulbodies produces infinite analytical strategies and endless series of expressions and propositions.

Darkness could fuel experimental onto-epistemological communal, collective, and collective processes where one-in-relation-to-another can experience silenced solitude of knowing and silent knowing while screaming out loud. Silent knowing and sense of solitude happens at the same time when one might feel infinite and deep belonging to the "real" and infinite composition of sounds- belonging to everything (all molecules of the forest and objects in it) and nothing (absence). Belonging takes place without boundaries. "This "universal absence" is actually a wholly "unavoidable presence". Darkness fills nocturnal space, but it is replete with the "nothingness of everything" (Macauley, 2009, p. 65).

Insert your soulbodies here:

Furthermore, seeing and being seen form a continuously moving (methodological) sense space where objects become subjects at the same time when subjects become objects. This infinite (methodological) difference, movement, and unity is only possible in the absence of see-able and visible boundaries and as a result of the wonderer's ability to avoid or bypass the separation between one and other of the forest. "Difference must become the element, the ultimate unity; it must therefore 
refer to other differences which never identify it but rather differenciate it" (Deleuze, 1994, p. 56).

Ikään kuin vasara joka saa äkkiä silmät ja tuijottaa sillä naulaa hakkaavaa muuraria. Muurari näkee vasaran pahansuovat silmät, menettää varmuutensa ja iskee sormeensa. Muurari on vasaran herra, mutta vasara hallitsee häntä, sillä työkalu tietää tarkasti miten sitä on käytettävä, käyttäjä sitä vastoin tietää sen vain suunnilleen (Kundera, 1983, p.323)

Not only vision and seeing but also language and discourse fails to characterize or produce soulbodies. They can see and being seen, see and not being seen, not see and being seen, and not see and not being seen all at once. Language becomes confused and senses get blurred. From one event to another, from light to darkness soulbodies and their experiential and experimental enactments and formations shiftendlessly.

Methodological and ontological composition of soulbodies and new creations of unanticipated methodological doing-objects take place in the forest. Black night is hovering over, stillness and thickness of air removes researchers' and explorers' human subjectivity. Soulbodies breathe. Knowing breathes. Methodologies breathe. Ideas multiply. Nothing (seemingly) moves but everything changes.

Sometimes soulbodies follow the holes in the thickness of cold and they emulate rain drops of late fall air. Lighter dry air and random beams of light stimulate curiosity and produce unexpected connections. Soulbodies function as negatives that draw out lightness and build from various shades of darkness in different ways. Soulbodies breathe again- this time together in (un)imaginable unison. Soulbodies are small things and ecological processes, small thoughts spread everywhere- engaged in 
knowing without domination and "fractal thinking" (Mullarkey \& Smith, 2012, p.1).

Soulbodies are not representations but processes of forest matter(ing).

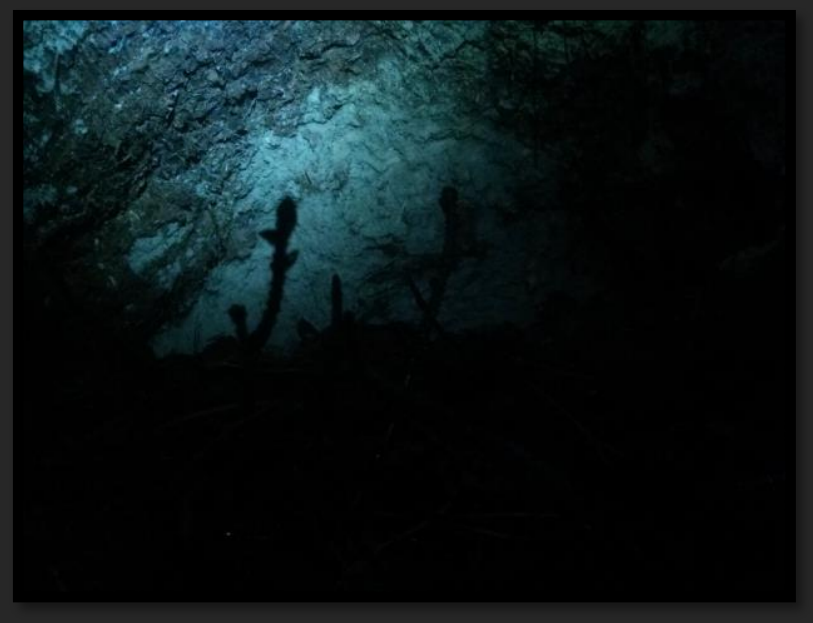

Soulbodies growing blue shadows

Darkness of the forest is likely to alter one's sense of time. Soulbodies bring time to the forest (world). World-time, material time, the occasion time are possible (see Laruelle, 2013). "In its non-philosophical sense, the "present" is no longer a dimension or even an ekstasis of time, but the ensemble of decisions-of-time already carried out or still to come in accordance with the World" (Laruelle, 2013, p. 147). Soulbodies decide the time not in deterministic or dominating ways but as "determination-in-the-last-instance" (Mullarkey \& Smith, 2012, p.2). Soulbodies hang on into time, fight time, and maybe forget time all at once. Maybe time forgets them. 


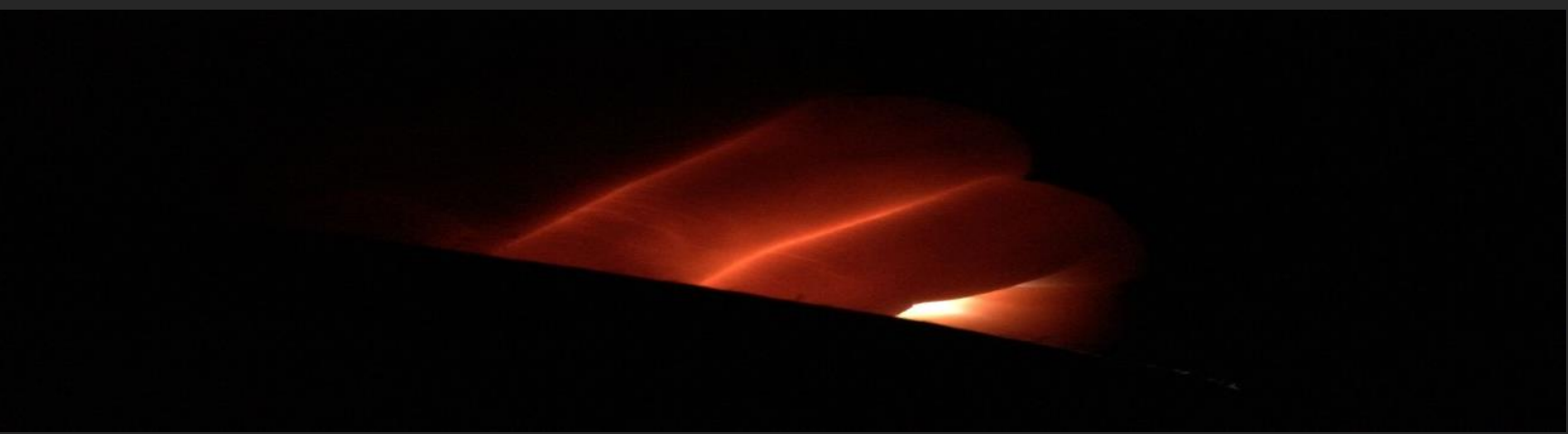

Our formations of soulbodies stay in the forest - they cannot be reproduced, lighted up, removed from the forest, or situated elsewhere. They belong to dark forest where they see, breathe darkness and dark matter(ing) (themselves). "We see projections, phantasms; we see externalizations or our irrepressible desires; we see things we could only see through eyes that are organs of the soul" (Kleinberg-Levin, 1988, p. 354). Seeing through continuously changing selves. Soulbodies produce themselves 
in, as, and through the active forces of nature and barely visible objects of the dark rainy forest. More soulbodies are formed. Unsteady landscape produces new soulbodies again and again. Repetition and improvisation seems to be one way to let go of habitual ways of being and doing (scholarship). Following Deleuze (1994), repetition is not to repeat the same but to experiment and expand through new beginnings; in this sense, repetition creates instantaneity. "To repeat is to behave in a certain manner, but in relation to something unique or singular which has no equal or equivalent (p.1)". Massumi writes in his prelude to the Manning's (2013) book that "events come in populations, and the populating takes the form of a serial iteration. From the point of view of their populating multiplicity, events are generic. But each event is utterly singular (p. xvi)". More-than-expressions and more-than-language may fuel the process of improvisation by 'letting go', moving beyond, and rethinking emerging and always changing functions and processes of soulbodies. Darkness places soulbodies in the creative threshold.

"The night holds us with special power; in its uncanny light, neither daylight nor total darkness, we see the forms of our projection: what we fear, what we dread, what we do not know because we cannot see" (Kleinberg-Levin, 1988, p. 380). (Methodologies of) darkness function as intimate spaces opening us up to the unlimited unknown. (Methodologies of) darkness function as unpredictable darkness events where lightness blinds us and darkness invites and creates. (Methodologies of) darkness function outside two dimensionality and binaries (e.g., light and dark, known and unknown...) creating different dimensionalities, spatial and affective possibilities for inquiry. (Methodologies of) darkness function as a move toward knowing-sensing-experiencing through blindness, slowness, sensitivities, connectedness, interrelatedness, and maybe through formation of new soulbodies. 
Soulbodies lived 25

Insert your souldbodies here: 


\section{Soulbodies infinitum}

seeing and being seen / seeing and not being seen

not seeing and being seen / not seeing and not being seen

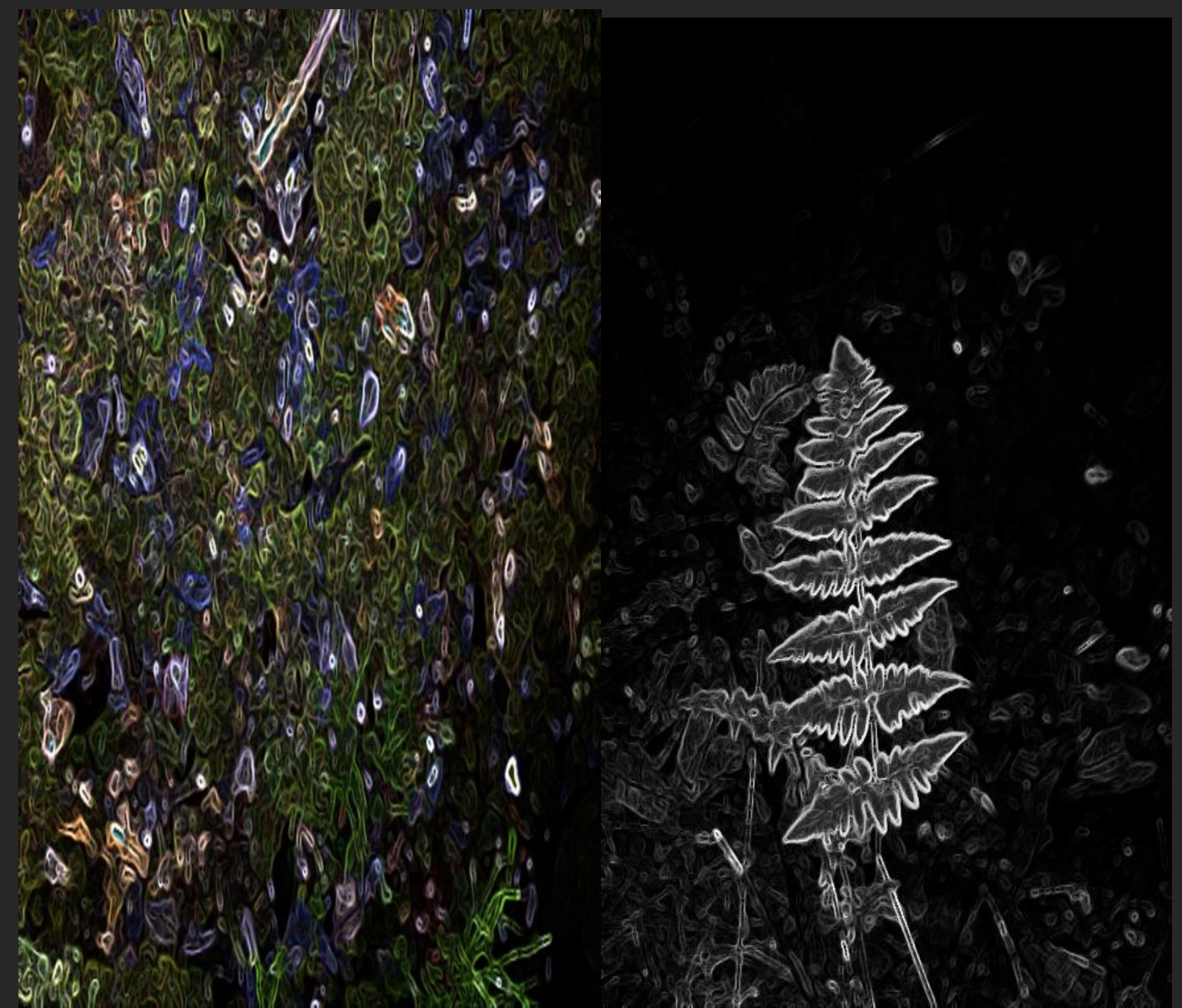


References:

Barad, K. (2012). On touching- the inhuman that I therefore am. A journal of feminist cultural studies, 23(3), 206-223.

Deleuze, G. (1994). Difference and repetition. (P. Patton, Trans.) New York: Columbia University Press.

Deleuze, G. (1990). The logic of sense (M. Lester, Trans.). New York: Columbia University Press.

Kleinberg-Levin, D. M. (1988). The opening of vision: nihilism and the postmodern situation (Vol. 1). New York: Routledge.

Koro-Ljungberg, M. (2016). Reconceptualizing qualitative research: Methodologies without methodology. Los Angeles: Sage

Kundera, M. (1983). Naurun ja unohduksen kirja (K. Siraste, Trans.). Helsinki, Finland: Werner Söderström Osakeyhtiö.

Laruelle, F. (2013). Dictionary of non-philosophy (T. Adkins, Trans.). Minneapolis: Univocal.

Macauley, D. (2009). Night and shadows. Environment, Space, Place, 1/2, 51-76.

Manning, E. (2013). Always more than one. Durham: Duke University Press.

Mullarkey, J., \& Smith, A. P. (2012). Introduction. The non-philosophical inversion: Laruelle's knowledge without domination. In J. Mullarkey \& A. P. Smith (Eds.), Laruelle and non-philosophy (pp. 1-18). Edinburgh: Edinburgh University Press.

Sorensen, R. (2008). Seeing dark things. The philosophy of shadows. Oxford: Oxford University Press. 